\title{
OPTIMIZING SUPPLY CHAIN IN REVERSE LOGISTICS
}

\section{T. SATHISH ${ }^{1} \&$ J. JAYAPRAKASH ${ }^{2}$}

${ }^{1}$ Research Scholar, Department of Mechanical Engineering, St. Peters University, Chennai, Tamilnadu, India.

${ }^{2}$ Professor, Department of Mechanical Engineering, Malla Reddy Engineering College, Secunderabad, Telangana, India

\begin{abstract}
New problems are introduced in reverse logistics by supply chain planning systems, which demand modern approaches. In this study, we have addressed the specific problem of the reverse logistics for EOL (end-of-life) products. This is to calculate the quantity of the products to be disassembled in the specific period of time in order to achieve the demand of multiple components during the specific period of time and also during the subsequent times. To solve the problem, excel programming based model was presented. The problem results provide the timing and the number of each product type to be disassembled. This is to achieve the components demand required at minimal disposal and disassembly costs. The methodology for obtaining the solution is illustrated with an example.
\end{abstract}

KEYWORDS: Disassembly, Remanufacturing, Reverse Logistics \& Supply Chain Planning

Received: Oct 20, 2017; Accepted: Nov 10, 2017; Published: Dec 06, 2017; Paper Id.: IJMPERDDEC201763

\section{INTRODUCTION}

Supply chain planning of end-of-life (EOL) products in reverse logistics has different traits of environmentally conscious manufacturing that includes reuse, remanufacturing, disassembly and recycling. Precisely, this is all about having a control on the manufacturing, distributing and user/customer return of products. Manufacturing returns include quality control returns, raw material surplus and production leftovers, whereas distribution returns include functional returns, commercial returns (e.g. wrong/damaged deliveries, unsold products) stock adjustments, and product recalls. At last, user/customer returns include warranty returns, service returns (spare parts and repairs), reimbursement guarantees, end of use and end of life. The manufacturers require efficient and effective Supply Chain Planning (SCP) strategies for products, components and materials, as they change to integrated network partners from being an isolated business unit. Reverse logistics process is sped up with the help of SCP, due to the online marketplace availability that supports the networking of environmentally conscious product suppliers, distributors, manufacturers and customers. By being a part of online market place, the manufacturers and their strategic partners and network of suppliers collaborate and conduct business over the internet. This results in reduced business cost and increases the efficiency of participants. The present study focuses on the supply chain planning system in reverse logistics, to find a way through which the manufacturers can reclaim multiple product models for remanufacturing. Reverse logistics' operational characteristics are different from the manufacturing characteristics. The challenging part is system modelling that facilitates both inter- and intra-enterprise supply chain networks that help to collect and remanufacture EOL products. The network should be designed as a supply chain where the products travel in both the directions. The forward supply chain shows the direction of the items flowing from manufacturers back to the users, as refurbished components or products. In this, a reverse supply chain shows the goods collected from the businesses and 
consumers back to manufacturers. The products collected in reverse direction may include product traded-ins, end-of-lease products, and the products that are sent back due to legislative requirements. Few of the special characteristics of the problems involving the reverse logistics are highlighted below.

\section{Supply/Demand Balancing}

One of the most expected difficult variables in the distribution of EOL returns or end-of lease products over the planning horizon. Unexpected demand/supply patterns are often faced by the predictors, which will depend on the success of the product and the competing products in the market.

\section{Accumulation}

Due to uneven market demands, certain kinds of parts of some components can be accumulated. For example, certain models like hard drives and memory chips have higher demands, whereas few other products without demand gets piled up on the floor.

\section{Logistical Network}

There are three different entities in the environment of reverse logistics supply chain management. They are disassembly plant, assembly plant and the recycling plant. Therefore, the planning should be from the point of larger perspective comprising these three entities. Alternation can be seen in the inventory policies in terms of the location of buffer stocks and the level. The products and components inventory should be properly maintained, from the process of products supply, collection, dismantling and recycling/reuse, in order to balance the demand and supply resources.

\section{Transportation}

Transportation cost of raw materials influences the decision on plant location. However, when disassembly and recycling is dealt with, there would be several folds increase in the control of products flow. This problem will have to be considered by the manufacturers and the locations for new assembly, disassembly or recycling have to be planned appropriately. The problems would increase when this is not considered, for instance, on the East Coast, where there is more demand for hundreds of used hard drives. It is most cost effective to dismantle the machines and ship only the required parts, or to ship the machines from West coast.

This study is mainly focused on the approach for systematic decision making to calculate the quantity of the products to be disassembled in the specific period of time in order to achieve the demand of multiple components during the specific period of time and also during the subsequent times. In RL, the decision making models are categorized into three groups including tactical, strategic and operational. This study is organized in operational level and as follows. The following section explains about the areas for planning for disassembly and remanufacturing which are very important aspects in RL. Section 3 discusses about environmental, economic and operational issues in reverse logistics. The problem statement is presented in section 4. Excel based procedure for optimizing RL is addressed in section 5. A procedure with case example is illustrated in section 6 . Finally, some conclusions are provided in section 7.

\section{BACKGROUND}

Remanufacturing is the process of producing products by using the already used parts that still meet required quality standards. This process helps in bringing back the worn-out products to new conditions, at significantly reduced rates. When compared with traditional manufacturing, re-manufacturing's planning and control cost is more complicated. 
Due to this, the development of analytical models for remanufacturing system analyzing becomes challenging. In re-manufacturing system, one important requirement is the necessity to disassemble the reclaimed products based on the components demand. The area of product disassembly in previous works can be classified in two divisions based on the employed techniques like planning and scheduling, and the application of methodology of mathematical optimization.

\section{Discussions}

In order to fulfil the components demand, many authors have had a look at the product disassembly. Taleb and Gupta put forth an algorithm for planning the disassembly of a discrete, well-structured product. The newly developed algorithm determines the schedule for disassembling the components so that the components demands are satisfied.

Hyun Bok Lee (2010) established an EOL decision model to facilitate remanufacturing for remanufacturing options. Disposal and remanufacturing are considered as the feasible options among the EOL options. Lot-sizing problem for disassembly of products has been addressed by Veerakamolmal in 1999. To find an optimal lot-size of products to disassemble, he developed a model for integer programming. To increase the economic value, we need to take an integrative approach to EOL-option decision-making by linked two steps.

A technique was optimized by Veerakamolmal in 1998 by which bi-directional supply chain system was optimized using a reverse flow (from return products/end-of-life, or the end of lease) for remanufacturing the products. To find the number of components to be retrieved for remanufacturing in different time periods, the technique uses the MRP (Materials Requirement Planning) approach, with a predicted demand for some remanufactured materials within a planning horizon. Lee (2004) says that the "like-new" products are given back to the customers after remanufacturing. According to Dong (2003) and Moore (1998), disassembly sequencing meets the issue of determination of the correct operations order in separating a product into constituent groupings or parts.

\section{PROBLEMS ENCOUNTERED IN REVERSE LOGISTICS}

\section{Economic Problems}

There has been a tremendous growth in last few years in the demand for durable consumer materials. This fastened improvement and development has given rise to increased demand, which resulted in decreased lifetime of the products. This in turn has resulted in the increase in the quality of used products that are scrapped. The scrap comes in bulk from household appliances, automobiles, electronic materials, and from computers at an increasing rate. The value of the returned materials can decrease in reverse logistics more than their new materials. Reverse supply chain's process expedition for driving the value preservation is quite critical. The complexity of RL when coupled with rapidly increasing returns volumes, makes the problem more complicated.

\section{Environmental Problems}

The growing requirement for waste disposal acts as the most prominent evidence for our environmental issues. Initially, the municipal wastes were land filled in large quantities. But, we are now less dependent on land filling as this has posed to be a dangerous environmental risk due to its location. This is also because that the lands have been filled up, which results in very dangerous risks to the health of all the organisms as the ground water becomes toxic due to water contamination This study is mainly focused on the approach for systematic decision making to calculate the quantity of the products to be disassembled in the specific period of time in order to achieve the demand of multiple components during the specific period of time and also during the subsequent times. In RL, the decision making models are categorized into 
three groups including tactical, strategic and operational. This study is organized in operational level and as follows. The following section explains about the areas for planning for disassembly and remanufacturing which are very important aspects in RL. Section 3 discusses about environmental, economic and operational issues in reverse logistics. The problem statement is presented in section 4. Excel based procedure for optimizing RL is addressed in section 5. A procedure with case example is illustrated in section 6 . Finally, some conclusions are provided in section 7.

\section{Operational Problems}

The following type of questions needs answers:

- How many machines should be ordered to disassemble the demanded parts?

- What are the economical machines to be used to dismantle evaluating fair market value of the machine?

- Should the machines be dismantled when the fair market value or current residual value is greater than the parts' sum (e.g., 5-6 parts are usually valuable for computers like display panel, HDD, motherboard, memory, CD-ROM drive)?

- Should the system select the machines that provide more reliable part, so that when the model's yield is greater or equal to other machines that meet demand of parts when dismantled (e.g., 100 demanded parts can be seen in Machine 2 \& Machine 1). However, Machine 2 shows 50\% reliability and Machine 1 has 80\% reliability.

In the operational level, the decisions refer to day-to-day decisions. At this level, the usual operations and disassembly ensures on-time delivery of the products to the customers. One of the other two issues at this level is disassembly sequencing.

\section{PROBLEM STATEMENT}

The primary aim of the developed model is to offer a cost efficient way through which the products can be reclaimed by the manufacturers for remanufacturing. The products' supply is assumed to be finite, which have been disposed as waste by the life-time end. As there is eminent shortage in their supply, possible shortage in the components supply for remanufacturing is also observed. This method accounts for ordering new (additional) components/component inventory in order to fulfil the demands. Once the disassembly is done, the waste materials and components are taken for proper disposal or recycling. Inventory of only few components are maintained due to the possibility in deterioration of some retrieved components. There may be some variation in the shelf life of each component. Our assumptions are:

- Each type of used product ( $\mathrm{Si}$ ) has an upper limit, which is available from the distributors during each time period.

- Any number of used products could be ordered by the dissembler from each type (up to a maximum of $\mathrm{Si}$ ) from the distributors to fulfil the components' demand at each time period. The new components fulfil any additional need.

- The factors of quality control are accountable for the possibility in products damage due to normal tear and wear when used, or due to some mishaps during their disassembly, collection, or retrieval processes.

- The components that have no demand will be sent for disposal or recycled for materials after the process of disassembling the products. 
- The components that are on demand were sorted into defective lots and good quality. The components that are found to be defective are sent for disposal or for recycling. If the components are of good quality, they can be utilized, thus these are sold to the manufacturers. If the shelf lives of good quality materials are zero and if they cannot be utilized in the current time (over-supply), they are sent for disposal or recycled. Or else, they can also be sent for sale in the subsequent periods. To determine the products' lot-sizes for disassembly, we present a procedure of supply chain optimization to fulfil the requirements of components for remanufacturing. If there is considerable level of shortage in the supply of reusable components, the procedure optimizes the products' lot-size in each period of time to disassemble. A process planner is also provided along with a detailed material retrieval plan, which leads to improvised CRP performance in the environment of RL supply chain.

\section{PROCEDURE}

Step 1: Required data is give as input such as: planning horizon's length $(T)$, products demand to remanufacture and increased supply of products $(S i) t$ (EOL or obtainable from all the product distribution center) in period $t,(1 \leq t \leq T)$. Furthermore, product specific information is prepared such as: the components multiplicity and commonality, the disassembly times, the value, the demand, the recycling cost factor, the weight, and the cost index for disposal for each component. Set $t=1$.

Step 2: After the quality percentages have been accounted for, determine the maximum yield for demanded materials.

Step 3: To fulfil the demand, assess to check if each of the components is available and then go to Step 5. For shortage adjustment, proceed to Step 4.

Step 4: To make up the shortages, the number of components to be ordered from outside sources should be calculated. Any potential shortage would be addressed by placing an order for obtaining new components that are available by reducing from the Net Requirements.

Step 5: The excel model should be formulated and solved. As per the demonstration in Gupta et al.12, using the reusable components that are on demand, the maximum product supply and the component/ product specific information, avail the number of products to order for the net profit (or loss) from the resale and disassembly, disposal of components and recycle.

Step 6: CRP table is updated. The number of defective components must be reduced from the component yield, for the present time period. Since the damaged materials are disposed and/or recycled in the same period, the modified number of discarded components in period $t$ becomes the sum of the damaged and actual component yield

Step 7: Check if the entire planning horizon has been scheduled $(t=T)$. If yes, go ahead with Step 8 . If not, set $t=$ $t+1$ and go to Step 2 .

Step 8: Stop.

\section{CASE EXAMPLE}

We shall illustrate the application of the supply chain optimization procedure through a case example. A computer company remanufactures two new computer models like PC5 and PC6 and distributes it. At the end of the lease terms, 
these utilize the components of other four computer models like PC1, PC2, PC3 and PC4. Let the Ordering and Assembly Lead Times (RT and RT) be one period each and planning horizon be 10 periods each. Just assumed that disassembling of the items can be done in the same period they are provided.

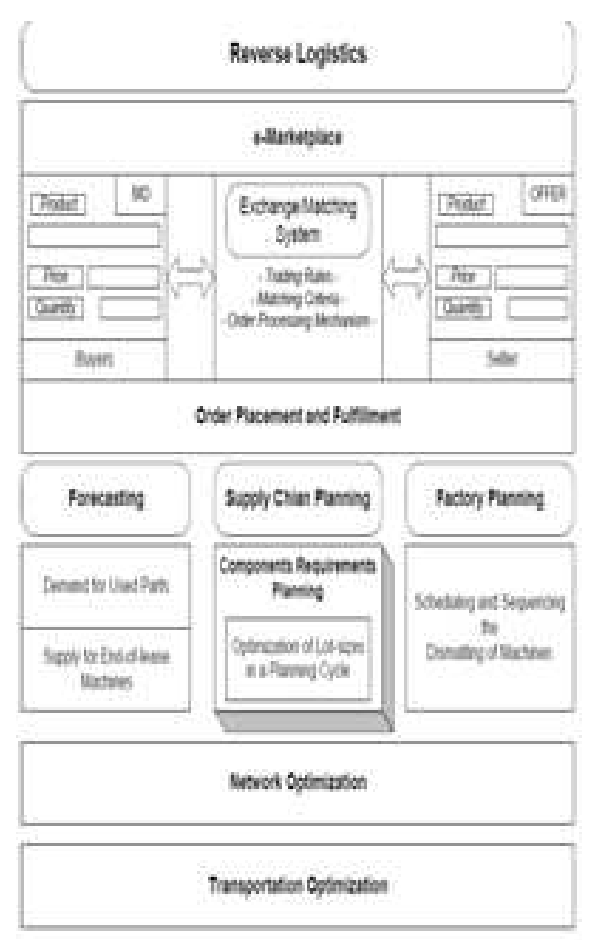

Figure 1: Supply Chain Planning Model for Reverse Logistics
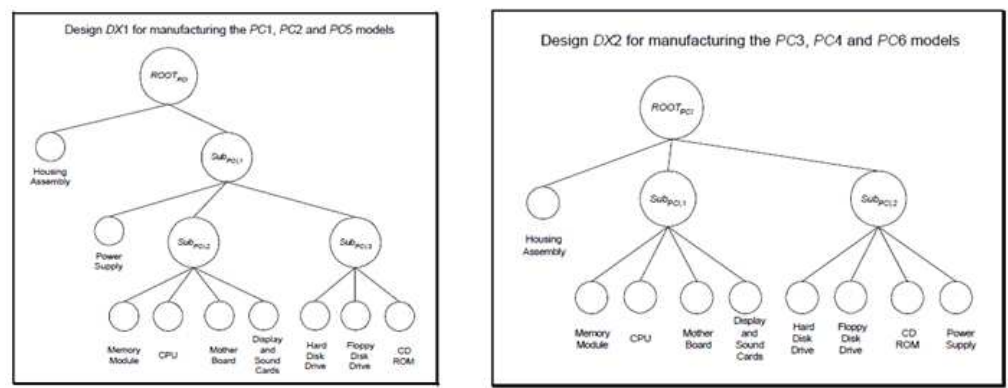

Figure 2: Product Structure for Models Pc1, Pc2 and Pc5

Figure 3: Product Structure for Models Pc3, Pc4 and Pc6

A sample of the input data is shown in the tables 1 and 2, which is necessary on every component of each product. In the previous section, the procedure has been explained. This could be applied to the example using the components yield, input data, the partial listing of CRP and the optimization result in each period as shown in the tables 3,4 and 5 . The results show that the lead times for disassembly and assembly shown drastic effects on the supply chain behavior, which results in oversupply for certain extent and intensive shortages (tables 3 and 4). It is assumed in this case example that the demand figures include seasonal effects of customer demand. A higher no. of computers are tend to be ordered by the customers in periods nine and ten. CRP results show that there are shortages in period 7 of components 14, 13 and 9, and in period 8 of components $9,13,14$, and 15, with the total two periods' lead time, even though there is ample supply of products in periods 9 and 10. Therefore, this suggests that in the RL supply chain, wherein the computers are usually traded/swapped in the same period, full advantage cannot be taken by the manufacturers on the reusable components 
recovered from the traded-in products to complete the remanufactured products' demand, if the lead times of disassembly and assembly are long. The product structure design might influence the preference due to its disassembly. It should be noted that over PC1 and PC2, the preference is given for PC3 and PC4. This is partially because of the fact that PC1 and PC2 requires more time to disassemble than PC3 and PC4, which also shows its influence on the cost. Another reason is that PC3 and PC4 are built with more advanced components, which are also very expensive. This turns to be more attractive for retrieval. Therefore, goods built with components of greater value will make remanufacturing more appealing in the reverse logistics supply chain, provided, standardized procedures are available for disassembly, collection and retrieval.

Table 1: Supply Chain and Demand Management

\begin{tabular}{|c|c|c|c|c|c|c|c|c|c|c|}
\hline 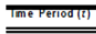 & 1 & 2 & 3 & 4 & 5 & 6 & 7 & 8 & 9 & 10 \\
\hline \multicolumn{11}{|l|}{ Supply } \\
\hline PC1 & 75 & 75 & 75 & 50 & 50 & 45 & 45 & 30 & 0 & 0 \\
\hline$P C 2$ & 65 & 70 & 105 & 90 & 90 & 80 & 80 & 75 & 0 & 0 \\
\hline$P C 3$ & 85 & 70 & 100 & 100 & 90 & 85 & 100 & 115 & 0 & 0 \\
\hline$P C 4$ & 85 & 105 & 110 & 145 & 130 & 130 & 150 & 140 & 0 & 0 \\
\hline \multicolumn{11}{|l|}{ Demand } \\
\hline PC5 & 0 & 0 & 95 & 100 & 110 & 120 & 85 & 70 & 135 & 150 \\
\hline PC6 & 0 & 0 & 100 & 125 & 125 & 100 & 95 & 125 & 150 & 150 \\
\hline
\end{tabular}

Table 2: Components Structure of Computers

\begin{tabular}{|c|c|c|c|c|c|c|c|}
\hline \multirow{3}{*}{$\begin{array}{l}\text { Component } \\
\text { Number }\end{array}$} & \multirow[t]{3}{*}{ Component Name } & \multicolumn{6}{|c|}{ Multiplicity $(0 i j)$} \\
\hline & & \multicolumn{4}{|c|}{ Supply } & \multicolumn{2}{|c|}{ Demand } \\
\hline & & $P C_{1}$ & $\mathrm{PC2}$ & $\mathrm{PC} 3$ & POA & $P Q$ & $P C 5$ \\
\hline 1 & Housing Assembly $(P C 1, P C 2)$ & 1 & 1 & - & - & - & - \\
\hline 2 & Housing Assembly $(P C 3, P C 4)$ & - & - & 1 & 1 & - & - \\
\hline 3 & Memory Module, 16 MB, SDRAM & 2 & - & - & - & - & . \\
\hline 4 & Memory Module, 32 MB, SDRAM & 2 & 4 & 2 & - & 2 & 2 \\
\hline 5 & Memory Module, 64 MB, SDRAM & . & - & 2 & 4 & 2 & 2 \\
\hline 6 & Pentium $\| 350 \mathrm{MHz}$ CPU and Heat Sink & 1 & . & . & - & - & - \\
\hline 7 & Pentium II $400 \mathrm{MHz}$ CPU and Heat sink & . & 1 & 1 & . & 1 & . \\
\hline 8 & Pentium II $450 \mathrm{MHz} \mathrm{CPU}$ and Heat Sink & - & - & - & 2 & - & 2 \\
\hline 9 & Mother Board $(P C 1, P C 2, P C 5)$ & 1 & 1 & . & . & 1 & . \\
\hline 10 & Mother Board $(P C 3, P C 4, P C 6)$ & . & - & 1 & 1 & . & 1 \\
\hline 11 & Display and Sound Cards $(P C 1-P C 4)$ & 1 & 1 & 1 & 1 & - & - \\
\hline 12 & $4 \mathrm{~GB}$ Hard Drive & 1 & - & . & - & - & - \\
\hline 13 & $9.1 \mathrm{~GB}$ Hard Drive & - & 1 & 2 & - & 2 & - \\
\hline 14 & 12.6 GB Hard Drive & - & - & - & 2 & - & 2 \\
\hline 15 & 1.44-MB Diskette Drive & 1 & 1 & 1 & 1 & 1 & 1 \\
\hline 16 & $32 X C D-R O M$ Drive $(P C 1, P C 4)$ & 1 & 1 & 1 & 1 & . & - \\
\hline 17 & Power Supply $(P C 1, P C 4)$ & 1 & 1 & 1 & 2 & . & . \\
\hline
\end{tabular}

Table 3: Components Yield for the Case Example

\begin{tabular}{|c|c|c|c|c|c|c|c|c|c|c|}
\hline Periods & , & $=$ & $=$ & 4 & - & $\circ$ & ? & $"$ & . & 10 \\
\hline \multicolumn{11}{|c|}{ Supply of Products } \\
\hline PC, & 70 & to & 75 & $\infty 0$ & so & 40 & 45 & so & 0 & 。 \\
\hline$P C 2$ & os & to & los & -o & -o & mo & no & 70 & - & 。 \\
\hline ec 3 & so & 70 & 100 & 100 & $\infty$ & 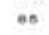 & 100 & $\cdots$ & - & - \\
\hline$P C 4$ & as & 105 & wo & 145 & 130 & 130 & 100 & 140 & o & 。 \\
\hline \multicolumn{11}{|c|}{ Yield of Component $P$, } \\
\hline P. & 140 & t4s & 1 no & +40 & 140 & 128 & 128 & tos & 。 & 。 \\
\hline D. & 170 & 170 & 210 & 240 & 220 & 210 & 250 & $25 s$ & 。 & 。 \\
\hline P. & 100 & 150 & 100 & 100 & 100 & oo & $\infty$ & $\infty$ & a & o \\
\hline D. & $\infty e 0$ & s70 & $>70$ & 000 & 040 & - & ono & 000 & . & 。 \\
\hline e. & ne & 000 & 0.0 & 700 & 700 & 000 & 100 & 700 & . & 。 \\
\hline D. & 7o & 70 & 70 & 00 & so & s. & 45 & 30 & - & 。 \\
\hline e. & 180 & 140 & 205 & 100 & 100 & 100 & 100 & $+\infty$ & 。 & 。 \\
\hline ค. & 170 & 210 & 220 & 200 & 200 & 200 & soo & $2 m a$ & 0 & 。 \\
\hline P. & a & 10. & 120 & $\infty$ & $\infty$ & $\| 7$ & $\| 7$ & $\Rightarrow$ & . & 。 \\
\hline P. & 127 & 191 & 107 & tos & tos & 100 & 107 & tor & 0 & 。 \\
\hline$P \ldots$ & SוO & 320 & 300 & 300 & 300 & 340 & 370 & 300 & 0 & 。 \\
\hline P.s & 70 & 70 & 78 & Do & so & 40 & 40 & so & 0 & 。 \\
\hline P... & ina & 107 & 228 & 27 & 202 & , 18 & סו & 220 & 。 & 。 \\
\hline e.. & 127 & 107 & 100 & 217 & tos & 100 & 220 & 210 & $\circ$ & - \\
\hline P.. & 248 & 200 & בונ & 300 & 200 & 272 & 000 & 200 & 0 & 。 \\
\hline P... & $3+0$ & $x \geq 0$ & soo & 300 & 200 & 240 & oro & 300 & . & 。 \\
\hline P.. & 308 & 428 & 000 & $=30$ & 400 & 470 & 028 & 000 & 0 & 。 \\
\hline
\end{tabular}


Table 4: Number of Disassemble Models

\begin{tabular}{|l|c|c|c|c|c|c|c|c|}
\hline \multicolumn{1}{|c|}{ Time Periods(Months) } & $\mathbf{1}$ & $\mathbf{2}$ & $\mathbf{3}$ & $\mathbf{4}$ & $\mathbf{5}$ & $\mathbf{6}$ & $\mathbf{7}$ & $\mathbf{8}$ \\
\hline Number of Product PC1 to Disassemble & 71 & 71 & 52 & 38 & 30 & 18 & 43 & 28 \\
\hline Number of Product PC2 to Disassemble & 65 & 70 & 105 & 90 & 90 & 80 & 80 & 75 \\
\hline Number of Product PC3 to Disassemble & 60 & 65 & 76 & 94 & 68 & 52 & 98 & 110 \\
\hline Number of Product PC4 to Disassemble & 73 & 102 & 108 & 132 & 126 & 128 & 148 & 138 \\
\hline$\quad$ Item P1 & & & & & & & & \\
\hline Number of Components Discarded & 615 & 635 & 680 & 550 & 510 & 410 & 535 & 440 \\
\hline$\quad$ Item P2 & & & & & & & & \\
\hline Number of Components Discarded & 133 & 167 & 184 & 226 & 194 & 180 & 246 & 248 \\
\hline$\quad$ Item P3 & & & & & & & & \\
\hline Number of Components Discarded & 142 & 142 & 104 & 76 & 60 & 36 & 86 & 56 \\
\hline Item P4 (Share life=1, Quality=100\%) & & & & & & & & \\
\hline Gross Requirements & 390 & 450 & 470 & 440 & 360 & 390 & 570 & 600 \\
\hline receipts from external sources & 0 & 0 & 0 & 0 & 0 & 0 & 0 & 0 \\
\hline Available balance & 0 & 102 & 206 & 184 & 196 & 70 & 32 & 24 \\
\hline Net requirement & 390 & 348 & 264 & 256 & 164 & 320 & 0 & 600 \\
\hline On hand from disassembly & 522 & 552 & 676 & 624 & 556 & 460 & 602 & 576 \\
\hline Number used from disassembly & 390 & 348 & 264 & 256 & 164 & 320 & 0 & 600 \\
\hline Number of new components required & 0 & 0 & 0 & 0 & 0 & 0 & 0 & 0 \\
\hline Number of Components Discarded & 0 & 0 & 0 & 0 & 0 & 0 & 0 & 0 \\
\hline
\end{tabular}

Table 5: Modified Excel Model

\begin{tabular}{|c|c|c|c|c|c|c|c|c|c|c|}
\hline 4 & $\mathrm{~A}$ & 5 & D & F & 7 & 8 & $\mathrm{H}$ & $T$ & 1 & 8 \\
\hline 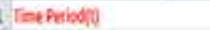 & 1 & 2 & 3 & t & 5 & t & 1 & 1 & , & to \\
\hline אI & $x$ & 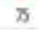 & $\pi$ & 30 & $\$$ & 5 & 45 & $\infty$ & 0 & 0 \\
\hline 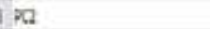 & 65 & $\pi$ & $\boldsymbol{s}$ & $x$ & $x$ & ๘ & ต & $\pi$ & 0 & 0 \\
\hline $\mathrm{xC}$ & 85 & 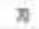 & $m$ & $w 0$ & $\infty$ & 8 & 10 & 18 & 0 & 8 \\
\hline $\mathrm{Pa}$ & 85 & 10 & $m$ & 15 & 130 & 19 & b: & 100 & D & 9 \\
\hline \multicolumn{11}{|l|}{ oneases } \\
\hline$k \mathrm{~s}$ & 0 & 0 & \% & $w$ & 100 & 20 & क & $x$ & 15 & 15. \\
\hline pos & 0 & 0 & $m$ & 15 & IDS & $2 x$ & 5 & 125 & 180 & 150 \\
\hline \multicolumn{11}{|l|}{ 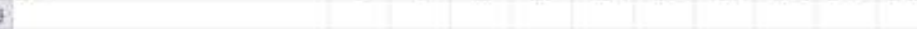 } \\
\hline \multicolumn{11}{|l|}{0} \\
\hline \multicolumn{11}{|l|}{1} \\
\hline \multicolumn{11}{|l|}{ 2. } \\
\hline \multicolumn{11}{|l|}{ (1) mate? } \\
\hline termponet Numbes & $\mathrm{\alpha} \mathrm{L}$ & $\mathrm{BO}_{2}$ & NO3 & ka & ics & $N a \dot{a}$ & & & & \\
\hline 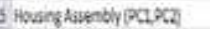 & 1 & 1 & . & - & . & . & & & & \\
\hline 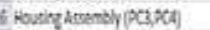 & & - & 1 & 1 & - & . & & & & \\
\hline 2 Wenony Wosde JSYS, Desu & 2 & . & . & . & 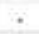 & . & & & & \\
\hline I Hemm uncis thes cosis & , & a & , & - & , & , & & & & \\
\hline
\end{tabular}

\section{CONCLUSIONS}

To solve the problem with the supply chain planning in the reverse logistics, an optimization-based procedure was used. Finding the most economical blend of goods to disassemble in each period of the planning horizon is the main goal. This is done by ensuring that the disassembling is done to accomplish the demand for various types of reusable machineries, while retaining the quantity of the products that are discarded partially in check, and incur the least cost for disposal. Once the issue is resolved, the no. of each product type to be disassembled is provided in order to achieve the components demand that is required at minimal disposal and disassembly costs. Therefore, when seen from supply chain point of view, this would result in minimal inventory supplies at both the end - supply of disassembled components and EOL products - of the RL chain. For managing RL, some guidelines are given below:

- Create strong processes and infrastructure to set a strong base.

- Challenge to manage numerous creativities from design, to maintenance, to production, to end-of-lease management, remanufacturing, and to disposal. 
- Enable the combined predicting and planning work between the part sales functions, supply/demand coordinator and logistics.

- By handling the flow via the supply chain, preserve the value, thus decreasing the cycle time.

- $\quad$ Timely disposition decisions are provided to decrease inventory rates.

\section{REFEREENCES}

1. Veerakamolmal and S. M. Gupta, "Optimal Analysis of Lot-Size Balancing for Multiproducts Selective Disassembly", International Journal of Flexible Automation and Integrated Manufacturing, vol. 6, no. 3\&4, pp. 245-269,1998.

2. S. M. Gupta, Y. J. Lee, X. Zanthopulos and P. Veerakamolmal, “An Optimization Approach for A Reverse Logistics Supply Chain”, Proceedings of the International Group Technology and Cellular Manufacturing Conference, March 26-29, San Juan, Puerto Rico, 2000.

3. S. M. Gupta and K. Taleb, “Scheduling Disassembly”, International Journal of Production Research, vol. 32, no. 8, pp.18571866, 1994.

4. K. Taleb, S. M. Gupta and L. Brennan, "Disassembly of Complex Products with Parts and Materials Commonality", Production Planning and Control, vol. 8, no. 3, pp. 255-269, 1997.

5. K. Taleb and S. M. Gupta, "Disassembly of Multiple Product Structures”, Computers and Industrial Engineering, vol.32, no. 4, pp. 949-961, 1997.

6. J. A. Isaacs and S. M. Gupta, "A Decision Tool to Assess the Impact of Automobile Design on Disposal Strategies”, Journal of Industrial Ecology, vol. 1, no. 4, pp. 19-33, 1997.

7. Md. Asif Equbal et al., A Comprehensive Supply Chain Performance Measurement and Evaluation (CSPME) Methodology, International Journal of Mechanical and Production Engineering Research and Development (IJMPERD), Volume 7, Issue 2, March - April 2017, pp. 1-18

8. V. D. R. Guide Jr., R. Srivastava and M. S. Spencer, "An Evaluation of Capacity Planning Techniques in a Remanufacturing Environment", International Journal of Production Research, vol. 35, no. 1, pp. 67-82, 1997.

9. Sathish, T. and Jayaprakash, J. "Meta-Heuristic Approach to Solve Multi Period Disassembly-To-Order Problem of End-OfLife Products using Adaptive Genetic Algorithm”, International Journal of Mechanical \& Mechatronics Engineering IJMMEIJENS, Vol. 15, pp. 59-67, 2015.

10. Sathish, T., Jayaprakash, J. and Thinakaran, N. "Multi-Agent Based Disassembly Sequencing and Planning For End-Of-Life Products”, Applied Mechanics and Materials, Vol. 814, pp. 1193-1197, 2015. 
